\title{
Thermal Investigations of Double Pass Solar Air Heater with Two Types of Porous Media of Different Thermal Conductivity
}

\author{
Jalal M. Jalil (i) a, Shrooq J. Ali ${ }^{\text {b* }}$ \\ ${ }^{a}$ University of Technology, Electromechanical Engineering Department, Baghdad Iraq. \\ 50003@uotechnology.edu.iq \\ ${ }^{\mathrm{b}}$ University of Technology, Electromechanical Engineering Department, Baghdad Iraq. \\ 50677@uotechnology.edu.iq
}

Submitted: 08/05/2020 Accepted: 08/09 2020

Published: 25/01/2021

\section{K E Y W O R D S}

Thermal efficiency, Double pass solar air heaters, Porous media, Thermal conductivity.

\begin{abstract}
A B S T R A C T
This study describes an experimental investigation of the thermal efficiency of stainless steel mesh and steel wool as a porous medium in the lower channel of a double pass solar air heater. An experimental setup was planned and developed. Various types of porous media with high thermal conductivity and with different porosities have been tested. The effects of the porosity of wire mesh, the thermal conductivity of porous media, mass flow rate, and the intensity of radiation have been studied. Experimental results show that thermal efficiency with using porous media is greater than without using porous media. When used steel wool as a porous medium, the thermal efficiency reached 79.82 percent while it can be achieved 76. The percent by using stainless mesh as porous material. The reduction in porosity increasing thermal efficiency. The thermal efficiency of multi-pass solar air collector when used steel wool as porous media is 6, 12.6 and31.7percent higher than without porous media at porosity 98.75, 97.5, and 96.25percent. While it can increase 8.1 and 28.5 percent at porosity 97.875 and 95.75 percent when using stainless steel as porous media.
\end{abstract}

How to cite this article: J. M. Jalil and S. J. Ali, "Thermal investigations of double pass solar air heater with two types of porous media have different high thermal conductivity" Engineering and Technology Journal, Vol. 39, Part A, No. 01, pp. 79-88, 2021.

DOI: https://doi.org/10.30684/etj.v39i1A.1704

This is an open access article under the CC BY 4.0 license http://creativecommons.org/licenses/by/4.0

\section{INTRODUCTION}

A solar air collector is a device that utilizes solar energy for heating air which acts as a heat exchanger converts solar energy into thermal energy in the transport medium [1]. Collectors are typically commonly used for drying agricultural products such as fruit, vegetables, seeds, industrial processes, and space heating. They are also used for applications of low to moderate temperatures [2]. There are two types of solar heaters, water heater, and air heater collectors. The production of air heating collectors is late relative to water heaters because of the lower thermal performance [3]. Solar collector's construction and maintenance are simple compared with liquid solar heating system, 
prevent leakage and corrosion problems. It is an environmentally Cozy device, with no emissions of greenhouse gases [4]. Solar Air Heating Systems also have some drawbacks like lack of consistency and reliability and affected by several factors, including latitude and clouds, etc. The small coefficient of heat transfer in the absorber plate and the air stream is one of the major problems, which leads to poor heat exchange between the passages and the air. [5], thus various modifications such as flow arrangements and design are suggested and implemented to increase the difference in the inlet and outlet temperature and thermal efficiency. These designs are based on the variation of the absorber plate or fin incorporation [6]. Adding porous materials in the passages of the solar collector [7] or make the plate into a corrugated absorbent plate to increase the air pass inside the solar collector [8].

One of the extensively studied improvements to Solar Air Heater (SAH) is the use of double pass airflow up and down its absorber plate to reduce heat losses, increase the air path inside the solar collector and thus increase its performance [9]. Saedodin 2017 et al. [10] studied the impact of porous metal foam on solar collector output numerically and experimentally. The researchers studied the effects of copper metal foam on thermal performance and the results showed that using the porous substrate improves the amount of Nusselt and average thermal efficiency up to $82 \%$ and 18.5\% respectively. Kareem, M. W 2017 et al. [11] investigated an enhanced induced multi-pass convective solar air heater (MPSAHC) system supported by granite pebble as porous media. The porous matrix exhibited slow energy discharge at night time with an air temperature difference of $14.27{ }^{\circ} \mathrm{C}$ at $18: 00 \mathrm{~h}$ to $4.54{ }^{\circ} \mathrm{C}$ at $24: 00 \mathrm{~h}$ over environmental air temperature. MPSAHC system delivered specific energy demand (SED) of $11.51 \mathrm{kWh} \mathrm{kg-1}$ while the maximum thermal collector and daily average transient collector efficiencies of $72.59 \%$ and $36.38 \%$ were achieved. N. F. Jouybari and T. S. Lundström 2020 [12] studied the effect of thin porous media have higher thermal conductivity covering the absorber plate of a solar collector. It is shown that the application of thin porous layers over the absorber plate improved the thermo-hydraulic and thermal efficiency of the solar collector significantly. The average improvement in thermo-hydraulic and thermal efficiency is higher than five times that was obtained in a non-porous medium solar heater while; the average increase in the porous solar heater friction factor is 2 times that of solar heaters with no porous media. Singh, S 2020 et al. [13] checked the DPSAH by using serpentine wavy wire-mesh as a packed bed experimentally and numerically. Results confirmed that the observed DPSAH's average instantaneous efficiency is around 74 percent with an improvement of 17 percent compared to SPSAH's. S. Singh 2020 [14] investigated the thermal performance of a porous serpentine wavy wire mesh as porous media in the double-pass solar heater. Experimental results demonstrated that the greatest thermohydraulic and thermal efficiencies for $93 \%$ porous found approximately $74 \%$ and $80 \%$ respectively. Approximately $18 \%$ and $17 \%$ higher than the single-pass, respectively.

The thermal efficiency of the SAH remains relatively low considering the various merits of the above-mentioned systematic literature survey and the numerous works presented. Many of the previous papers studied double pass solar air heater with porous media, as well as studied the effect of porosity on efficiency. In this work, an experimental investigation of double pass solar air heater is presented with two types of porous media have different high thermal conductivity (stainless steel and steel wool). The effects of mass flow rate, thermal conductivity, porosity, and intensity of radiation have been studied to reach high thermal efficiency as compared with without porous media.

\author{
List of symbols \\ A: Area of heat transfer $\left(\mathrm{m}^{2}\right)$ \\ $\mathrm{A}_{\mathrm{C}}$ : Collector channel surface area $\left(\mathrm{m}^{2}\right)$ \\ $\mathrm{D}_{\mathrm{h}}$ : Hydraulic diameter $(\mathrm{cm})$ \\ $\mathrm{U}$ : Velocity of air $(\mathrm{m} / \mathrm{s})$ \\ P: Perimeter of the cross-section (m) \\ $\mathrm{H}$ : Averaged heat transfer coefficient $\left(\mathrm{W} / \mathrm{m}^{2}\right)$ \\ K: Thermal conductivity (W/m.k ) \\ m: Mass flow rate $(\mathrm{kg} / \mathrm{s})$ \\ $\mathrm{T}_{\text {fout }}$ : Outlet air temperature $(\mathrm{K})$ \\ $\mathrm{T}_{\text {in }}$ : Inlet air temperature $(\mathrm{K})$ \\ $T_{a m}$ : Ambient Temperature (K)
}


$T_{P M}$ : Temperature of porous media $(\mathrm{K})$

$\mathrm{Q}_{\mathrm{u}}$ : Useful thermal energy $(\mathrm{kj} / \mathrm{s})$

$Q_{\text {in }}$ : Heat flux from the heater $(\mathrm{kj} / \mathrm{s})$

I: Intensity of solar radiation $\left(\mathrm{W} / \mathrm{m}^{2}\right)$

List of creek symbol

$\Phi$ : Porosity \%

$v_{v}$ : Volume of vacuum $\left(. \mathrm{cm}^{3}\right)$

$v_{t}$ : Bulk volume of material $\left(\mathrm{cm}^{3}\right)$

$\mu$ : Dynamic Viscosity of Air $(\mathrm{Kg} / \mathrm{m} \mathrm{sec})$

P: Density of Air $\left(\mathrm{Kg} / \mathrm{m}^{3}\right)$

Cp: Specific Heat J/(kg. k)

$\eta_{t h}$ : Thermal Efficiency ( \%)

List of abbreviations

DPSAH: Double pass solar air heater

SPSAH: Single-pass solar air heater

SAHs: Solar Air Heaters

MPSAH: Multi-pass solar air heater

PM: Porous Media

WPM: With Porous Media

WOPM: Without Porous Media

\section{EXPERIMENTAL SET-UP EQUIPMENT}

Photographically, the experimental apparatus is illustrated in Figure 1. The experimental apparatus consists of the following:

1) Solar collector (Main Test Section).

2) Tungsten halogen lamps (A solar simulator).

3) A centrifugal fan (blower).

4) A gate.

5) Temperature sensors (Thermocouples).

6) Measurement Devices:

a. Temperature measurement (Temperature Recorder 12 Channels).

b. Radiation measurement (Solar meter).

c. Hot-wire anemometer (Velocity measurement).

The experimental system was designed, developed, and tested. The simulators use 8 halogen lamps, each of which has $400 \mathrm{~W}$ of rated capacity. The dimmers are used to monitor the amount of solar radiation. The collector is made of aluminum and the dimensions of double pass solar air heaters are $125 \mathrm{~cm}$ long, $30 \mathrm{~cm}$ wide, and $11 \mathrm{~cm}$ in height. The height consists of two passages; the first passage (inlet) has a gap of $5 \mathrm{~cm}$ while the second passage (outlet) has a gap of $6 \mathrm{~cm}$. The length and width of the absorber plate are $120 \mathrm{~cm}$ and $30 \mathrm{~cm}$ respectively, the length of which is less than the length of the collector to return the airflow to the outlet. The glass has a thickness of $4 \mathrm{~mm}$. The insulation has been made available. At the beginning of the second channel, a $5 \mathrm{~W}$ centrifugal capacitance blower was mounted to pull the air. The airflow from the first channel also installs the porous media in the second channel as shown in Figure 2. The porous media Placed in a drawer made of aluminum which has nets towards the flow as shown in Figure 3. 


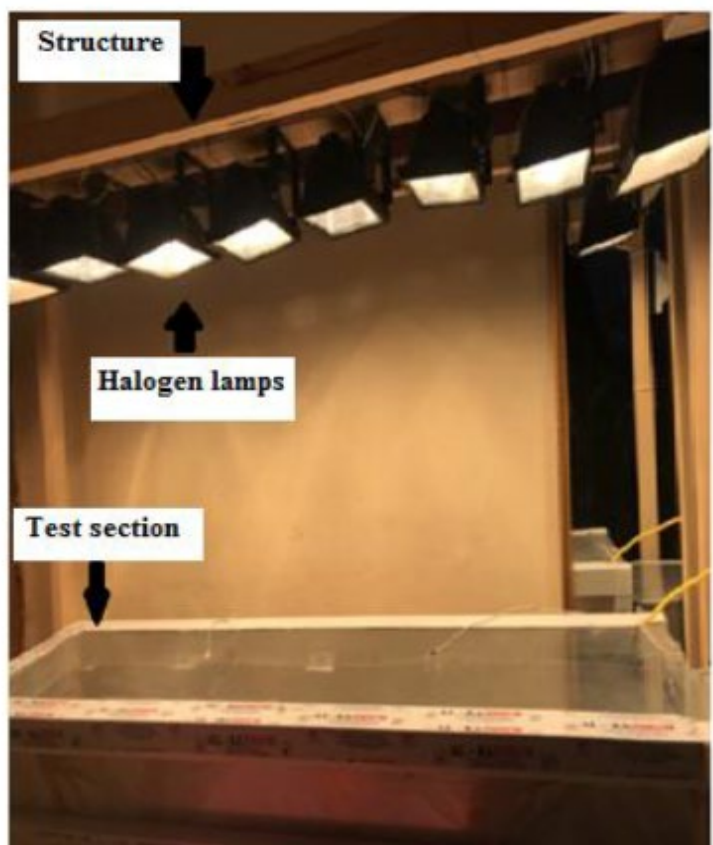

(A)

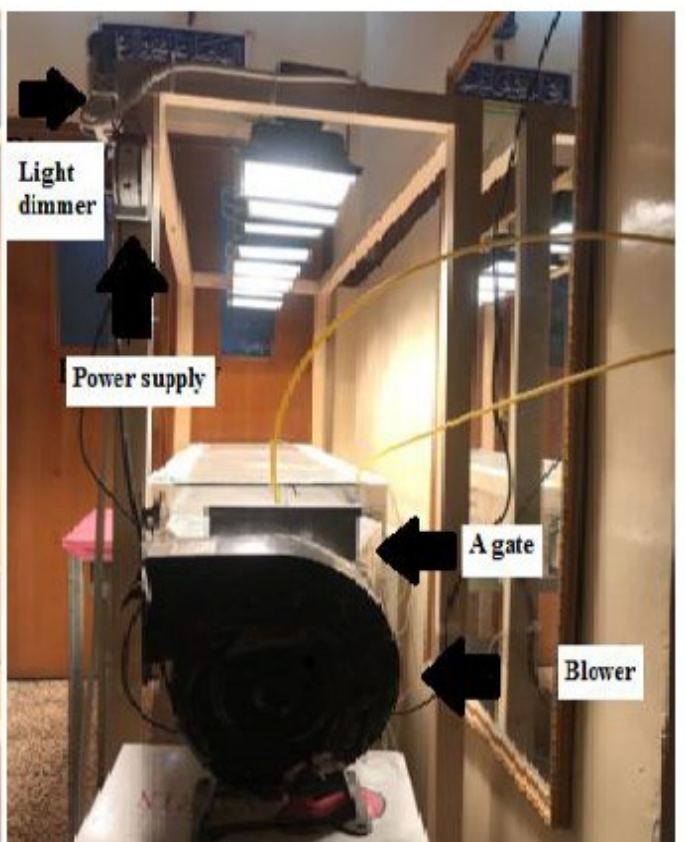

(B)

Figure 1: Experimental Setup (A) the front side and (B) the view side

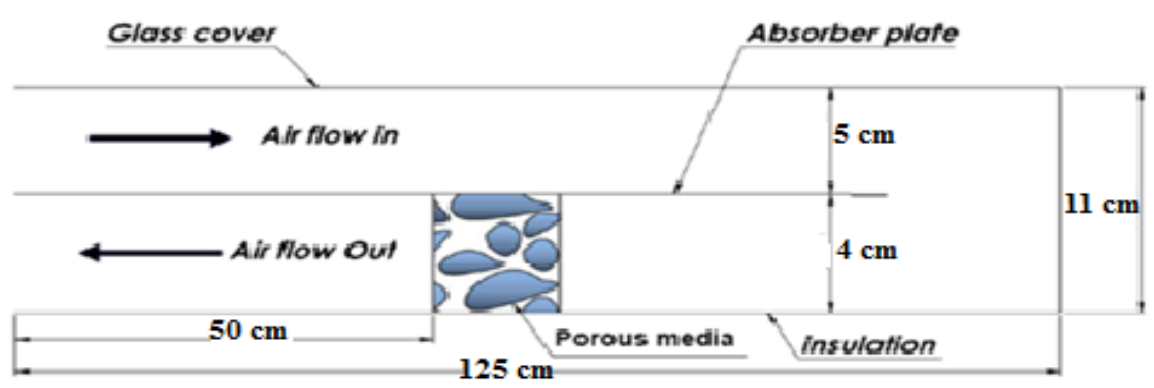

Figure 2: The schematic of a double-pass thermal solar collector with porous media in the second channel

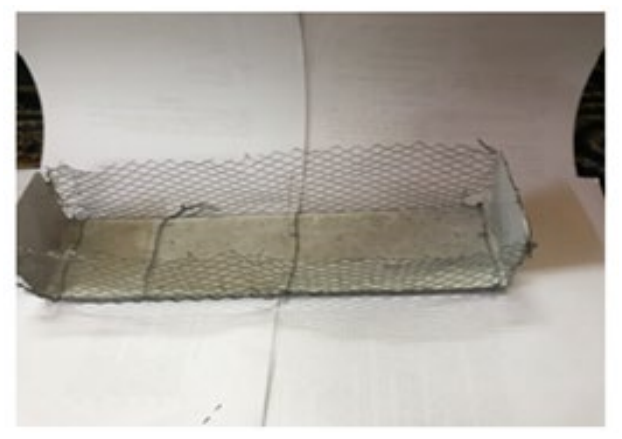

Figure 3: The drawer of porous media

The most common characteristic of a porous medium is its porosity that Can be described as the empty spaces inside a substance and is a proportion of the vacuum Size over complete volume, between 0 and 1 , or as a percentage between 0 and $100 \%$ and the void fraction is described the fraction of the flow-channel volume occupied by the air phase or as the fraction of the channel cross-sectional area occupied by the air phase. The porosity of a porous material can be represented as 


$$
\varphi=v_{v} / v_{t}
$$

Where $v_{v}$ the volume of vacuum is occupied by fluids and $v_{t}$ is the complete or bulk volume of material, including solid and vacuum parts [15].In this paper, there are two types of porous media (steel wool and stainless steel mesh) have been studied as shown in Figure 4. Stainless steel mesh has thermal conductivity equal to $20 \mathrm{~W} / \mathrm{m}$. K [16] and includes two cases. The first one consists of three layers of wire mesh which has a porosity of $97.87 \%$ and there is a $3.5 \mathrm{~cm}$ space between each other. The second case consists of six layers and there is $1.4 \mathrm{~cm}$ space between each other at porosity $95.75 \%$. The second type is steel wool wire mesh which has $50 \mathrm{~W} / \mathrm{m}$. K of thermal conductivity [17] at porosities $98.7,97.5$, and 96.25 percent.
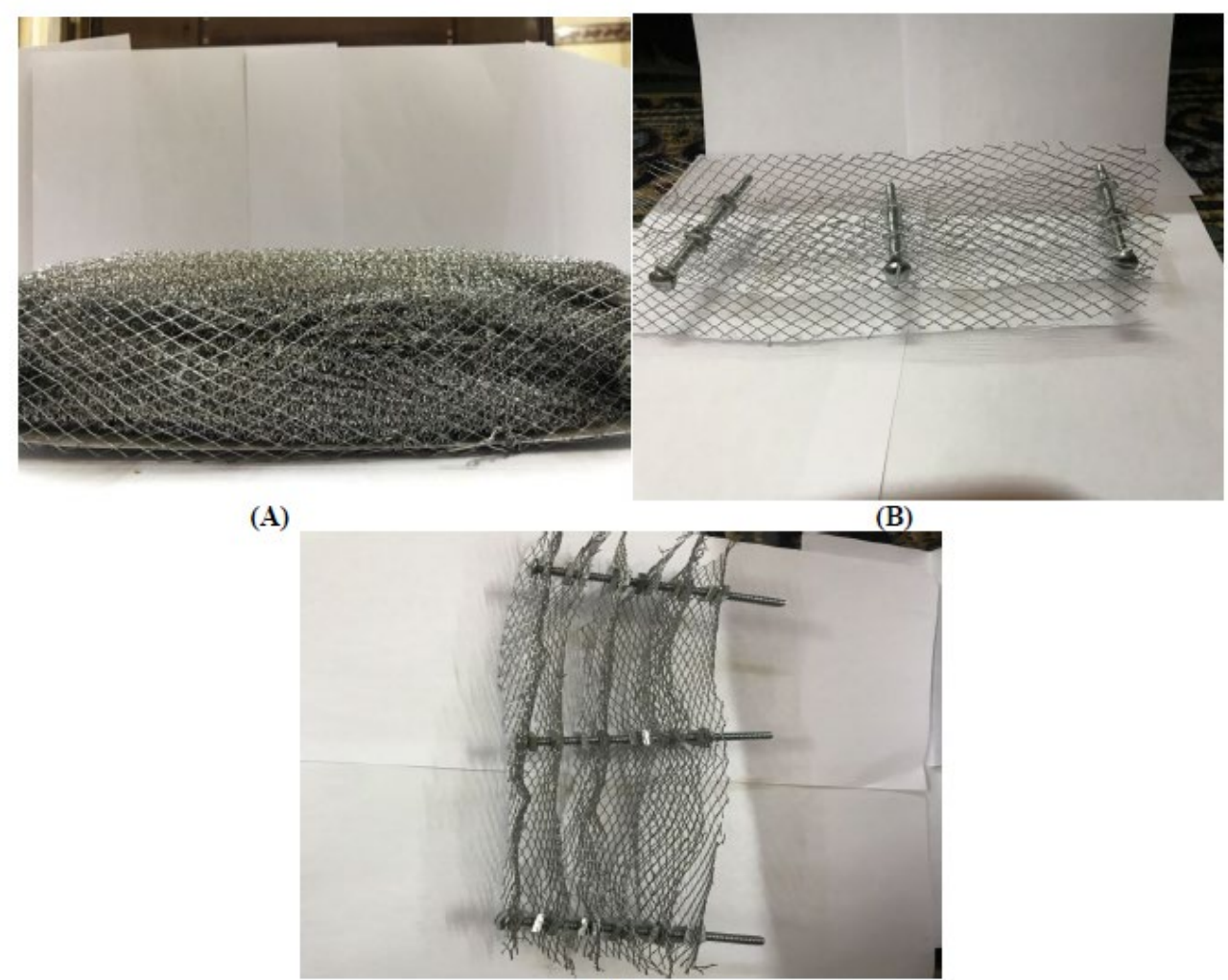

(c)

Figure 4: Types of porous media (A) steel wool (B) three layers of stainless steel mesh (C) six layers of stainless steel

\section{THEORY}

The thermal efficiency of the current design of solar air heaters will be calculated for evaluation. The estimation of the output parameters uses the calculated average air temperatures. Besides, the performance parameters also depend on the properties of the air which change with increasing or decreasing flux of solar radiation. The output parameters for the thermal efficiency of porous serpentine wavy packed bed canal solar air heater under single and counter airflow are calculated as [13]

The useful heat gain, $Q_{u}(\mathrm{~W})$ is indicated as

$$
\begin{gathered}
\mathrm{Q}_{\mathrm{u}}=\dot{\mathrm{m}} \mathrm{C}_{\mathrm{p}}\left(\mathrm{T}_{\text {fout }}-\mathrm{T}_{\text {fin }}\right) \\
\text { And } \dot{\mathrm{m}}=\rho \mathrm{uA}
\end{gathered}
$$

The solar air heaters thermal efficiency is measured as

$$
\eta_{\text {th }}=\frac{\mathrm{Q}_{\mathrm{u}}}{\mathrm{I} \mathrm{A}_{\mathrm{C}}}
$$


Where,

$\dot{\mathbf{m}}$ is the mass flow rate of air, $\mathrm{Cp}$ is the specific heat of air,

$\mathrm{T}_{\text {fin }}$ and $\mathrm{T}_{\text {fout }}$ are the inlet and outlet air temperatures, respectively,

$\rho$ is the density of the air,

$\mathrm{u}$ is the velocity of the air,

$A$ is the area of upper channel of flow

I is the intensity of the solar radiation

And $\mathrm{A}_{\mathrm{C}}$ the area of solar collector

\section{RESULT AND DISCUSSION}

Solar air collector with using porous media at the bottom of the air passage improves thermal efficiency as compared with solar air collector with double pass counter-flow without using porous media. This may be because the porous media provides a large surface area for heat transfer and hence the volumetric heat transfer coefficient is extremely high. In the counterflow system, the air flowing in the first air passage absorbs heat from the upper channel and then flows through the second channel. The relative error of all experimental curves ranges between (4-7) percent. Figures 5, 6 , and 7 show the effect of mass flow rate on temperature differences at different values of solar radiation with and without porous media. Temperature differences decrease with increased mass flow rate. Also, the temperature difference with using porous media (steel wool and stainless steel) is greater than without the use of porous media, due to increased heat transfer area and thermal conductivity of porous media resulting in increased output temperature. The maximum temperature difference reached $21.7^{\circ} \mathrm{C}$ when using steel wool as porous media meanwhile reached $20.3^{\circ} \mathrm{C}$ when using stainless steel at $0.01773 \mathrm{~kg} / \mathrm{s}$ of mass flow rate. Temperature differences also increasing with decreasing porosity (increasing in porous media and reduction in voids) that made the air to remain in test suction for a long time and then increase its temperature shown in Figure 8.

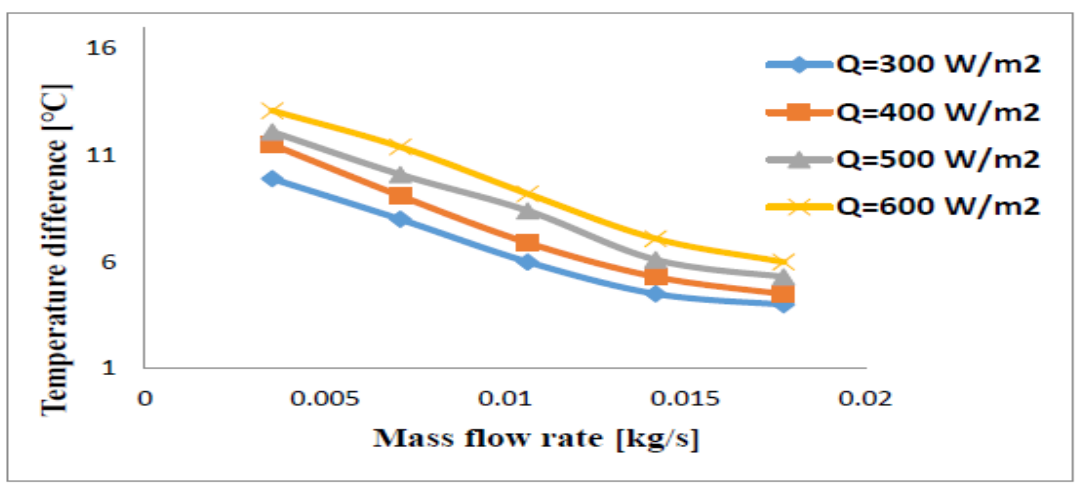

Figure 5: The effect of various mass flow rate on temperature difference without porous media

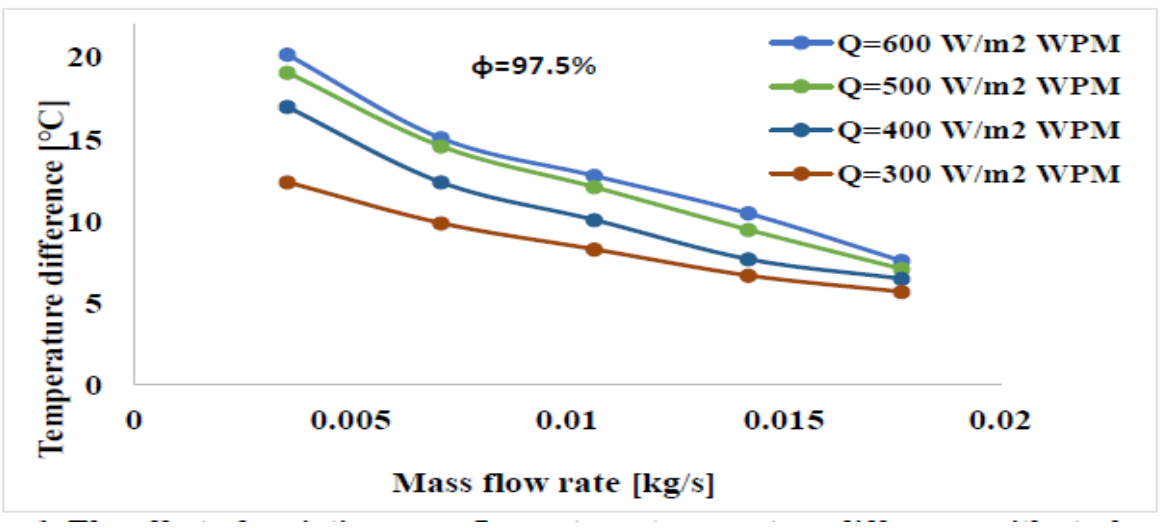

Figure 6: The effect of various mass flow rate on temperature difference with steel wool as porous media $(\varphi=97.5 \%)$ 


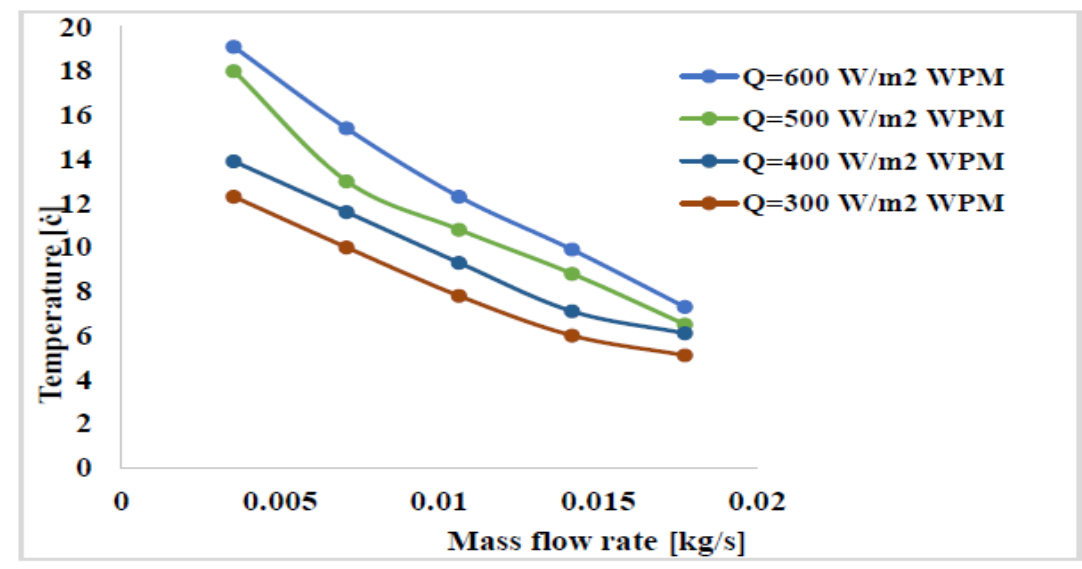

Figure 7: The effect of mass flow rate on temperature difference with stainless steel mesh as porous media

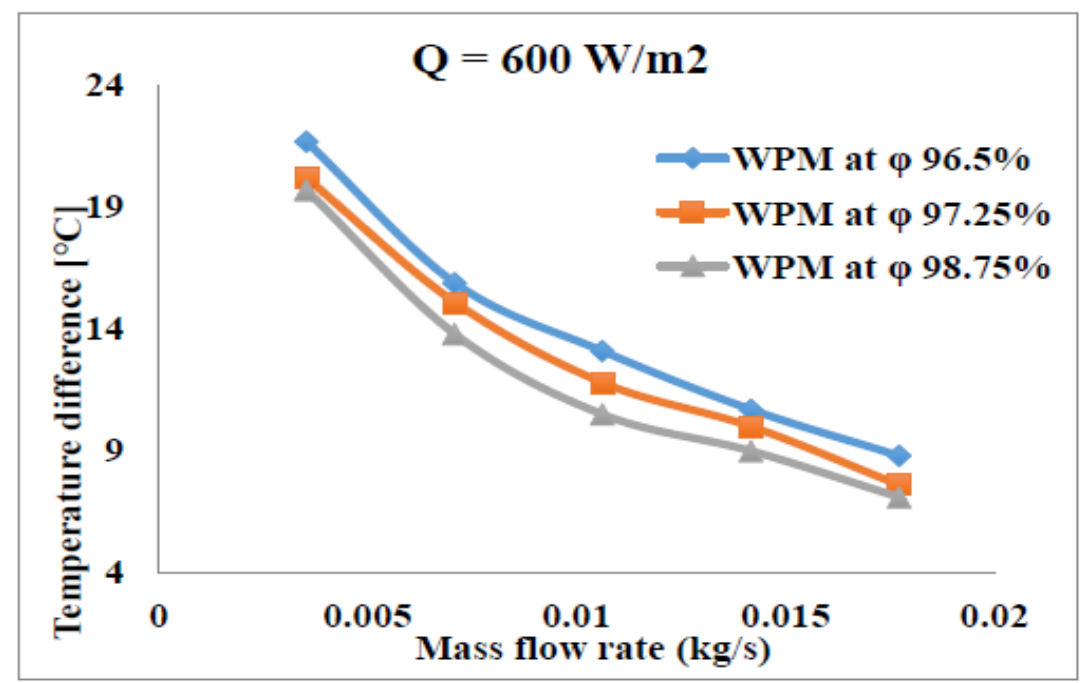

(A)

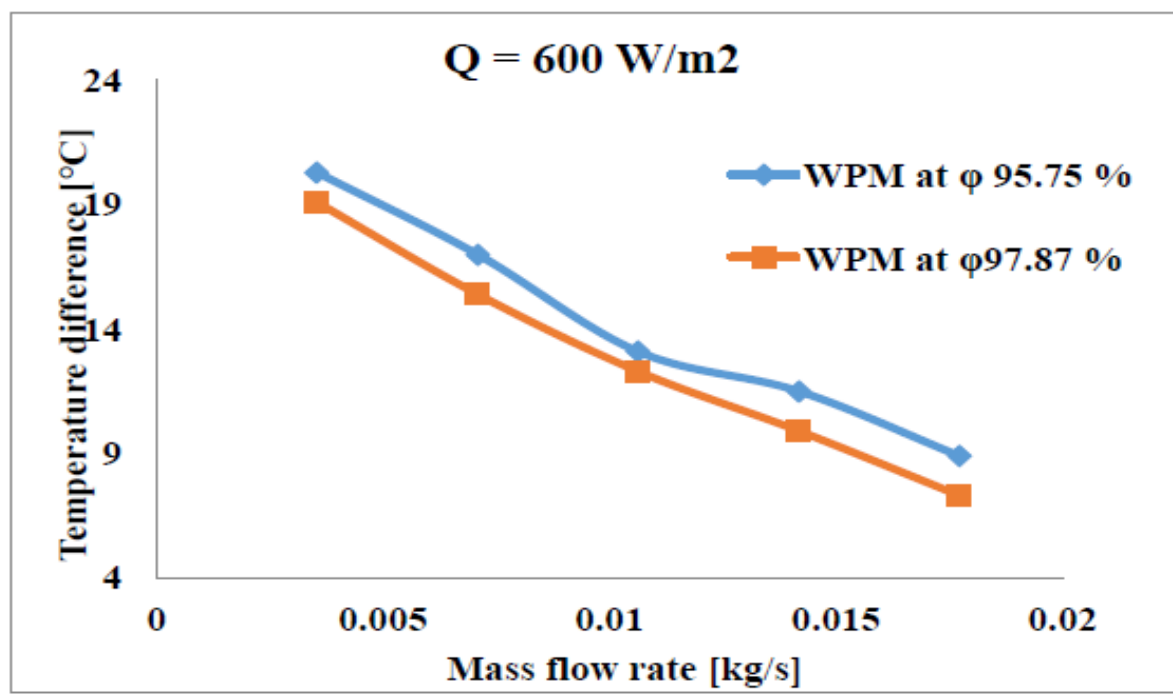

(B)

Figure 8: The impact of mass flow rate with porous medium on temperature difference at different porosities $\left(Q=600 \mathrm{~W} / \mathrm{m}^{2}\right)(\mathrm{A})$ steel wool (B) stainless steel mesh 
Figures 9 and 10 show the results of measured Thermal efficiency as a function of the double pass solar collector mass flow rate with and without porous media. The collector thermal efficiency increases with an increase in mass flow rate. It reaches a maximum point and then decreases because of the decrease in the temperature difference as the mass flow rate increase. Using porous media in the lower channel increase the heat transfer area and temperature rise, so the efficiency increases as temperature rise increases.

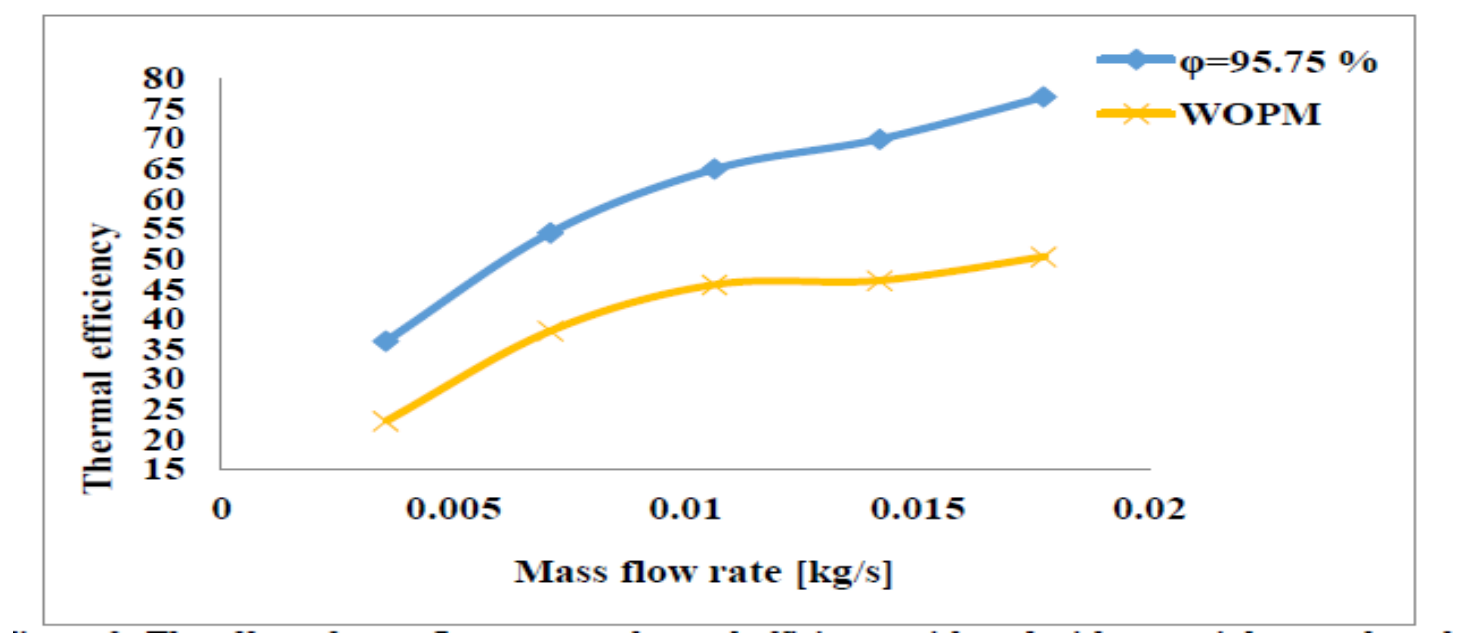

Figure 9: The effect of mass flow rate on thermal efficiency with and without stainless steel mesh

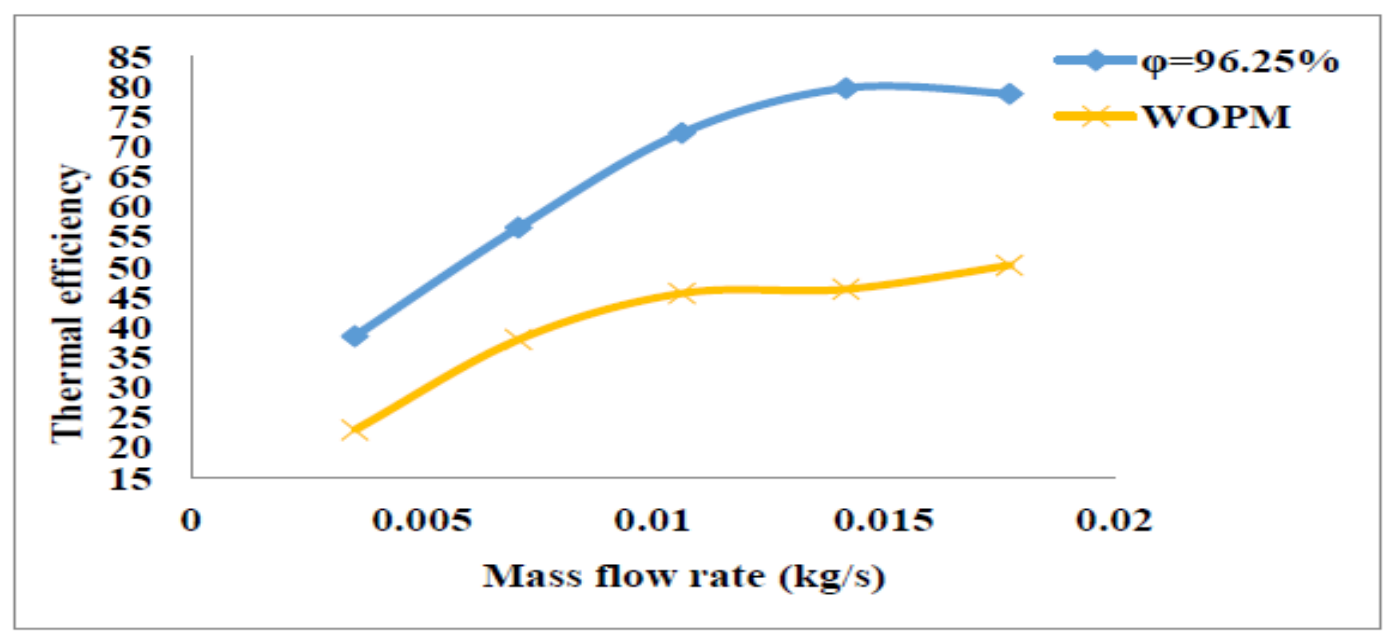

Figure 10: The effect of mass flow rate on thermal efficiency with and without steel wool

Figure 11 shows the effect of mass flow rate on thermal efficiency at different porosities of steel wool and stainless steel. The improvement in the thermal efficiency of double pass solar air collector with using steel wool as porous media is $6,12.6$ and 31.7 percent higher than without porous media at porosities 98.75, 97.5, and 96.25percent respectively. Meanwhile, increase 8.1 and 28.5 percent higher than without porous media at porosity 97.87 and 95.75 percent when using stainless steel as porous media at the same Conditions. Figure 12 shows the effect of thermal conductivity of porous media on thermal efficiency. It is found that when compared between the steel wool and stainless steel. The thermal efficiency reached $79.83 \%$ at $\mathrm{Q}=500 \mathrm{w} / \mathrm{m}^{2}$ and porosity equal to $97 \%$ when used steel wool meanwhile reached $76 \%$ when used stainless steel as porous media. This behavior can be explained as follows because the thermal conductivity of steel wool is higher than the thermal conductivity of stainless steel for that reason make steel wool more efficient at the same condition. 


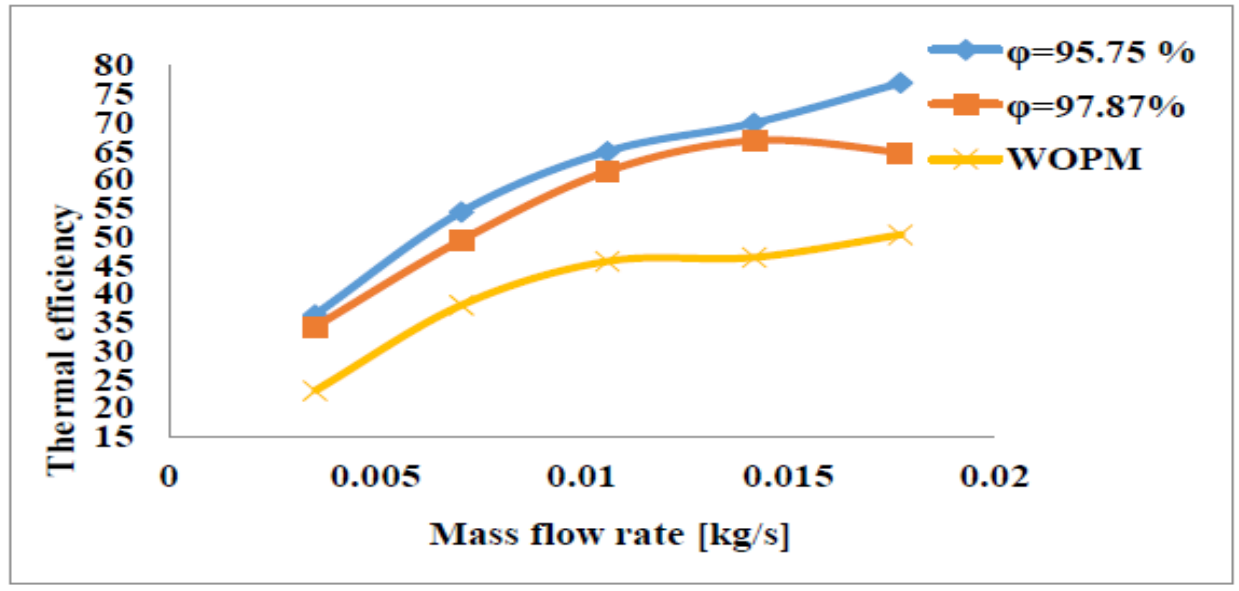

(A)

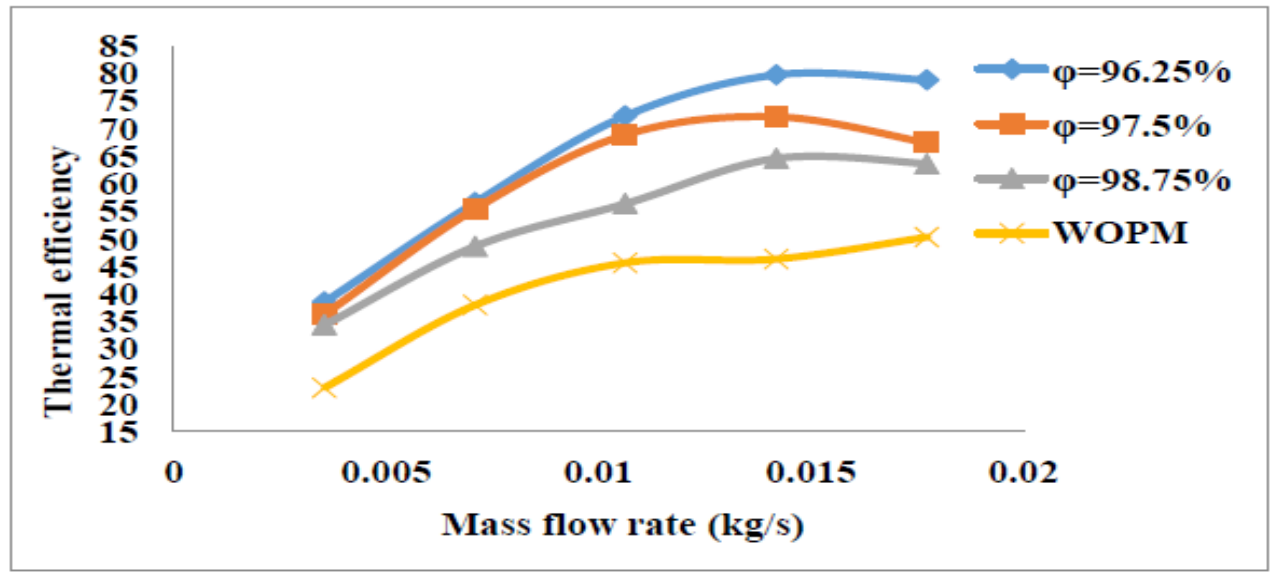

(B)

Figure 11: The effect of mass flow rate on thermal efficiency at $Q=500 \mathrm{~W} / \mathrm{m}^{2}$ and at different porosities (A) stainless steel mesh (B) steel wool

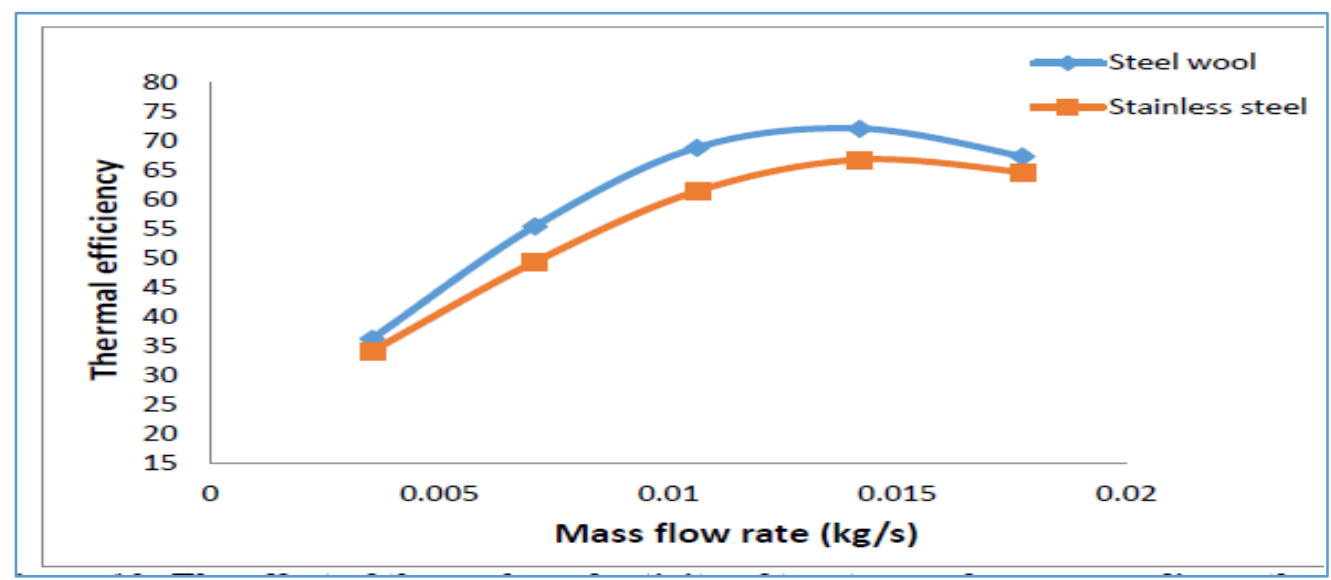

Figure 12: The effect of thermal conductivity of two types of porous media on thermal efficiency at porosity $97 \%$

\section{CONCLUSIONS}

Experimental research on the efficiency of the double pass solar air heater with porous media is carried out. Following conclusions have been drawn from this study:

Many methods can be used to develop the collector's output, so one of the most effective methods for improving thermal efficiency is using double pass solar air heaters with different types of porous 
media. Thermal efficiency can be reached $79.83 \%$ when used steel wool as porous media while it can be reached $76 \%$ when using stainless mesh as porous media. It noted that the thermal output of a double pass solar collector using porous media is affected by porosity. The reduction in porosity (reduction in the field of airflow) reduced the flow channeling; it increases the winding of the air path, which allows the air to remain in the system as long as possible and acquires heat from all sides of the collector, raising the thermal efficiency. The thermal efficiency of steel wool is higher than that of stainless steel since the thermal conductivity of steel wool is higher than that of stainless steel, making steel wool more effective in the same condition.

\section{References}

[1] A. Roy and Md. Emdadul Hoque. Performance analysis of double pass solar air heater with packed bed porous media in Rajshahi, AIP. Conf. Proc., 1851 (2017). https://doi.org/10.1063/1.4984639

[2] G. Maraba. An experimental study on enhancement of heat transfer in a solar air heater collector by using porous medium, Master's Thesis, İzmir Institute of Technology, 2012.

[3] B. M. Ramani, A. Gupt and R. Kumar. Performance of a double pass solar air collector, Sol. Energy., 84(2010)1929-1937. http://dx.doi.org/10.1016/j.solener.2010.07.007

[4] M. Y. H. Othman, K. Sopian, B. Yatim, and W. R. W. Daud. Development of advanced solar assisted drying systems, Renew. Energy., 31(2006) 703-709. http://dx.doi.org/10.1016/j.renene.2005.09.004

[5] S. J. S. Stanley, V. K. Anbarasan and K. K. Murugavel. Performances of packed bed double pass solar air heater with different inclinations and transverse wire mesh with different intervals, Therm. Sci., 20(2016)175-183. https://doi.org/10.2298/TSCI131015085S

[6] M. F. El-Khawajah, L. B. Y. Aldabbagh, and F. Egelioglu. The effect of using transverse fins on a double pass flow solar air heater using wire mesh as an absorber , Sol. Energy., 85(2011) 1479-1487. https://doi.org/10.1016/j.solener.2011.04.004

[7] J.Tian, T. Kim, T. J. Lu, H. P. Hodson, D. T. Queheillalt, D. J. Sypeck, and H. N. G. Wadley. The effects of topology upon fluid-flow and heat-transfer within cellular copper structures, nt. J. Heat. Mass. Transf., 47(2004) 3171-3186. https://doi.org/10.1016/j.ijheatmasstransfer.2004.02.010

[8] W. Lin,, W. Gao, and T. Liu. A parametric study on the thermal performance of cross-corrugated solar air collectors, Appl. Therm. Eng., 26(2006) 1043-1053. https://doi.org/10.1016/j.applthermaleng.2005.10.005

[9] T. Alam and M. Hoe Kim. Performance improvement of double-pass solar air heater-A state of art of review, Renew. Sustain. Energy Rev., 79(2017) 779-793. https://doi.org/10.1016/j.rser.2017.05.087

[10] S. Saedodin, S. A. H. Zamzamian, M. E. Nimvari, S. Wongwises, and H. J. Jouybari. Performance evaluation of a flat-plate solar collector filled with porous metal foam: Experimental and numerical analysis, Energy. Convers. Manag., 153(2017) 278-287.

[11] M. W. Kareem, S. I. Gilani, K. Habib, K. Irshad, and B. B. Saha. Performance analysis of a multi-pass solar thermal collector system under transient state assisted by porous media, Sol. Energy., 158(2017) 782791. http://dx.doi.org/10.1016/j.solener.2017.10.016

[12] N. F. Jouybari and T. S. Lundström. Performance improvement of a solar air heater by covering the absorber plate with a thin porous material, Energy, 190(2020) 116437. http://dx.doi.org/10.1016/j.energy.2019.116437

[13] S. Singh, S. K. Chaurasiya, B. S. Negi, S. Chander, M. Nemś, and S. Negi. Utilizing circular jet impingement to enhance thermal performance of solar air heater, Renew. Energy., 154(2020) 1327-1345. http://dx.doi.org/10.1016/j.renene.2020.03.095

[14] S. Singh Experimental and numerical investigations of a single and double pass porous serpentine wavy wiremesh packed bed solar air heater, Renew. Energy., 145(2020) 1361-1387. http://dx.doi.org/10.1016/j.renene.2019.06.137

[15] Fundamentals of Fluid Flow in Porous Media / Chapter 2: The Porous Medium / Porosity.

[16] https://www.engineeringtoolbox.com/thermal-conductivity-metals-d_858.html

[17] https:/www.google.com/search?sa=X\&rlz=1C1GTPM enIQ522IQ522\&biw=1366\&bih=657\&source=uni $\mathrm{v} \& \mathrm{tbm}=\mathrm{isch} \& \mathrm{q}=$ thermal + conductivity + of + steel \&ved=2ahUKEwj4w73znr7rAhWGzKQKHdXKC2MQsAR 6BAgIEAE 